\title{
Unusual Location of Rheumatoid Nodule Case Report
}

\author{
Lamya Walid AlAbdulrahman*, Syed Ali, Mojieb Al-Haque Manzary, Abdullah Al-Shaikhi and Wasim Fawzi \\ Raslan
}

Department of orthopedic, John Hopkins Aramco Healthcare (JHAH), Imam Abdulrahman bin Faisal University, Saudi Arabia

Submission: June 03, 2020; Published: June 22, 2020

*Corresponding author: Lamya Walid AlAbdulrahman, Department of orthopedic, John Hopkins Aramco Healthcare (JHAH), Imam Abdulrahman bin Faisal University 2346-Al Muntazah Ad Dammam 34242-7149 Kingdom of Saudi Arabia, Dhahran, Saudi Arabia

\section{Abstract}

Background: Rheumatoid arthritis (RA) is a chronic inflammatory disease that can lead to joint destruction. RA commonly associated with extra-articular manifestation. The most common musculoskeletal related extra- articular presentation is rheumatoid nodules. Rheumatoid nodule of foot and ankle is a rare presentation, reaching up to $1 \%$ of all cases. The diagnosis of the rheumatoid nodule is mainly clinical. Ultrasound and MRI are radiological studies that can support the diagnosis of the rheumatoid nodule. Treatment can be either conservative or surgical excision if symptomatic. Rheumatoid nodule usually affects the extensor aspect of the extremities and areas of frequent mechanical contact such as elbow and dorsum of the hand. We are presenting a case of an unusual location of the rheumatoid nodule on the anterior ankle that is reported previously in English literatures.

Case Report: A 59-year-old lady known case of seropositive rheumatoid arthritis presented to the orthopedic clinic with a chief complaint of a mass on the anterior left ankle. MRI revealed heterogeneous soft tissue mass with a central cystic component. The patient was planned for surgical excision of the mass under anaesthesia.

Conclusion: The physician should be aware of unusual locations of presentation of rheumatoid nodules. Surgical indications for this mass include pain and restriction of joint movement.

Keywords: Rheumatoid nodules; Anterior ankle mass; Dorsal foot mass; Rheumatoid; Ankle; Mass

Abbreviation: RA: Rheumatoid arthritis

\section{Background}

Rheumatoid arthritis (RA) is a chronicsystematicinflammatory disease that affects peripheral joints synovium causing synovitis and destruction of the articular surface [1]. Patients with RA can present with systematic extra-articular manifestation such as vasculitis, pulmonary fibrosis, and rheumatoid nodules [1]. We are presenting a case of an unusual location of a rheumatoid nodule on the anterior aspect of the ankle. Up to our knowledge, there is no such case has been reported in the literature before.

\section{Case Report}

A 59-year-old lady known case of seropositive rheumatoid arthritis for ten years, and it was complicated by pulmonary fibrosis. The patient is currently on leflunomide and occasional low dose of prednisone. The patient presented to the orthopedic clinic with a chief complain of anterior ankle mass that was increasing in size and associated with a previous history of occasional discharge and signs of inflammation that settled by an oral antibiotic. The patient has no other mass anywhere in the body. On examination, there was a mass on the left anterior ankle with healed sinus (figure 1). Palpation revealed a 3 X $2 \mathrm{~cm}$ firm, mobile mass that is not adherent to the underlying skin. The peripheral neurovascular exam was intact. Range of motion was restricted and painful.

The X-ray showed no bony or articular abnormalities (Figure 2). MRI was done, and it revealed $3.5 \mathrm{X} 2.5 \mathrm{X} 1.4 \mathrm{~cm}$ heterogeneous soft tissue mass with central cystic component over the anterolateral aspect of the dorsum of the left hindfoot (Figure 3 ). The patient was planned to have excision of the rheumatoid nodule under anaesthesia. After excision, the specimen was sent to the pathology lab for microscopic examination.

Histology showed a focal area of myxoid and collagenous degeneration admix with fibrinous material surrounded by histiocytic reaction (figure 4). 


\section{Orthopedics and Rheumatology Open Access Journal (OROAJ)}

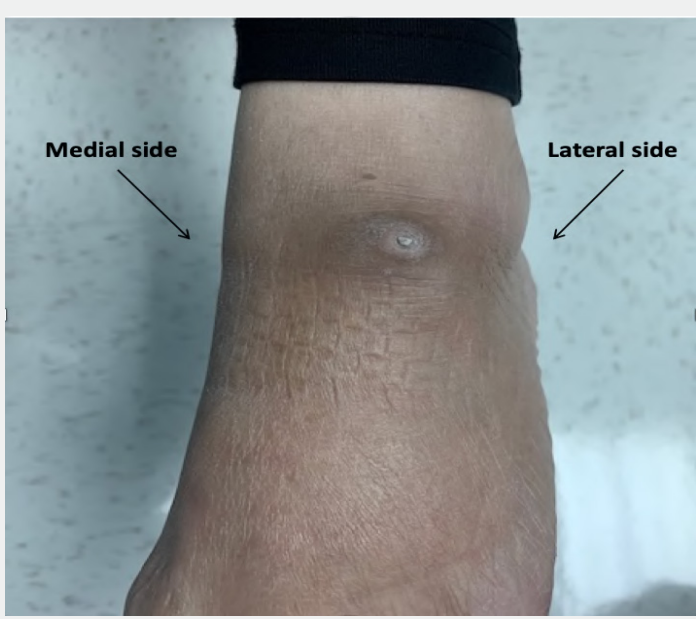

Figure 1: Chronic healed sinus on the site of nodule.

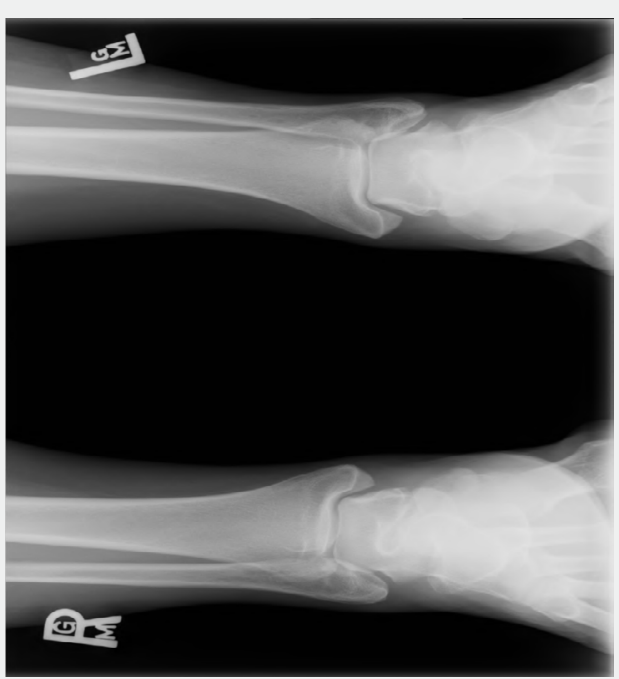

Figure 2: X-ray of left ankle and foot showing no bony or articular abnormalities.

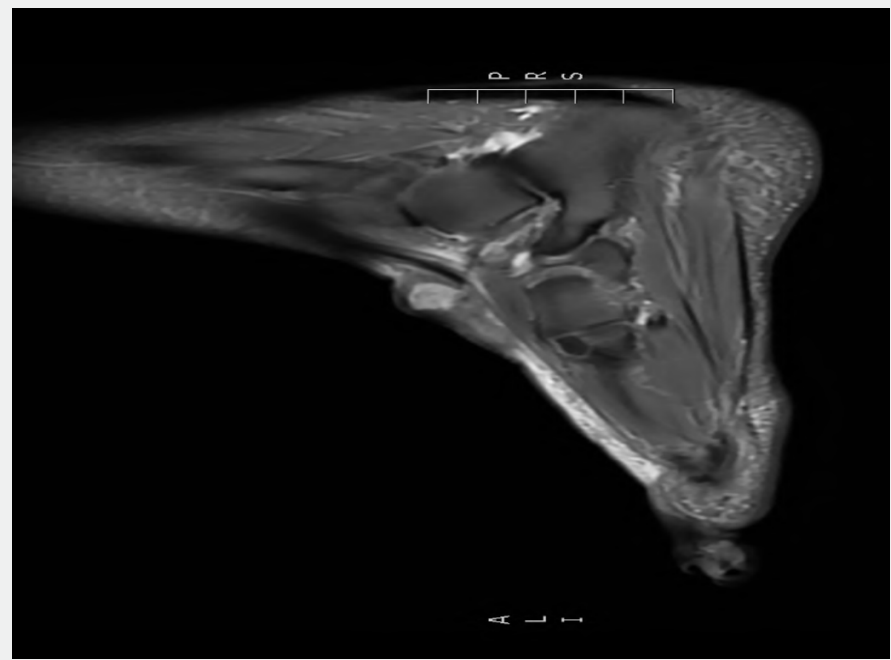

Figure 3: MRI image showing bilobed heterogenous soft tissue mass noted within the subcutaneous fat with central cystic component. 


\section{Orthopedics and Rheumatology Open Access Journal (OROAJ)}

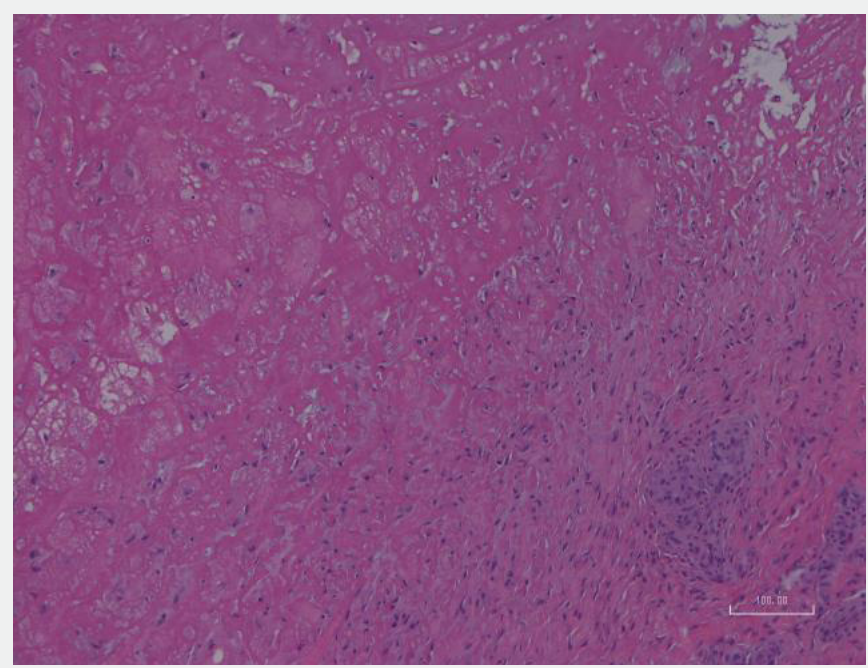

Figure 4: Wall of rheumatoid nodule exhibiting peripheral fibrous regeneration with central myxoid and fibrinous degeneration of collagen.

\section{Discussion}

Rheumatoid arthritis (RA) is a chronic systematic inflammatory disease that affects peripheral joints synovium causing synovitis and destruction of the articular surface [1]. A subcutaneous rheumatoid nodule is the most frequent cutaneous extra-articular manifestation that occurs in about $20 \%-35 \%$ of rheumatoid arthritis patients [2,3]. Rheumatoid nodule of the foot and ankle is a rare presentation that reaches up to only $1 \%$ of the cases [2]. Among these reported cases of foot and ankle rheumatoid nodules, there was no reported case of affecting the anterior aspect of the foot and ankle. All reported cases were located on the plantar surface, mainly on the heel [2-6]. A subcutaneous rheumatoid nodule is a superficial soft-tissue lesion that usually affects the extensor aspect of extremities and areas of frequent mechanical contact such as the elbow and dorsum of the hand in ambulated patients and occiput and sacrum in bed-bound patients $[1,7]$.

The exact pathogenesis behind the development of rheumatoid nodules is still unknown [7]. There are multiple theories regarding the pathogenesis of rheumatoid nodule. The common factor leading to rheumatoid nodule formation is repetitive trauma to the small vessels that trigger the aggregation of rheumatoid factors and other inflammatory complexes resulting in secondary inflammatory process activation and, eventually fibrin deposition [7]. Because of slow enzymatic and cyclic degradation, necrosis will develop, and palisading macrophages will enclose the necrotic area forming a rheumatoid nodule [7]. Diagnosis is mainly clinically based on the presence of palpable firm, subcutaneous soft tissue mass in patients with a positive rheumatoid factor, or those who are previously diagnosed with RA $[7,8]$. In literature MRI have been described to identify the morphology of rheumatoid nodule [9]. There are two morphological patterns observed on MRI [9]. The first pattern shows a cystic appearance with enhancing peripheral component, while the second pattern shows a solid appearance with uniform enhancement following gadolinium injection [9]. For a definite diagnosis, histological examination is the choice of investigation [7]. Histologically, rheumatoid nodule appears as an area of central necrosis enclosed by palisading epithelioid macrophages that are surrounded by a layer of granulation tissue composed of lymphocytes and histocytes [4,7]. Management of rheumatoid nodules is conservative unless infection, ulceration, or disabling symptoms present in which surgical excision is indicated [3]. The prognosis of untreated rheumatoid nodules is not consistent [9]. Some nodules may regress or resolve spontaneously, while others may maintain the same size or even increase enlarged $[9,10]$. In our case report, we reported a rare presentation of rheumatoid nodule that affects the anterior aspect of the ankle.

\section{Conclusion}

The physician should be aware of such a presentation of uncommon locations of rheumatoid nodules and consider it as a possible deferential for any soft tissue mass.

\section{Acknowledgement}

Pathology department at JHAH.

\section{References}

1. Smolen JS, Aletaha D, Mcinnes IB (2016) Rheumatoid arthritis. Lancet 388(10055): 2023-2038.

2. Ebru Taștekin, Murat Birtane, Serdar KilinÇ, Mert CiftdemiR, Ufuk Usta, et al. (2012) From Pathology to Diagnosis: A Symptom-Free Patient with a Rheumatoid Nodule in the Foot. Turkish Journal of Rheumatology 27(3):195-199.

3. Lee S, Yoo KH, Lee K, Kim IY, Kwon HJ, et al. (2015) Rheumatoid Nodulosis with Recurrent Nodules: A Case Report, pp. 241-245. 
4. McMurrich W, Thomson C, McKay N, McRorie E, Salter D, et al. (2014) Soft tissue swellings in the foot: Rheumatoid nodulosis. The Foot 24(1): 37-41.

5. Del Barrio-Díaz P, González S, Vera-Kellet C (2017) Painful Plantar Lesions: An Unusual Presentation for Rheumatoid Nodules. J Gen Intern Med 32(8): 955-956.

6. Horiuchi Y, Fujimoto H (1997) Bilateral Rheumatoid Nodule Development on the Distal Region of the Soles Poor Blood Circulation and Local Pressure as Possible Causes. J Dermatol 24(4): 273-274.

7. Tilstra JS, Lienesch DW (2015) Rheumatoid Nodules. 33(2015): 361 371.
8. Munns JJ, Ruff ME (2020) Rheumatoid Nodules. J Hand Surg Am 39(4): 765-767.

9. El-Noueam KI, Giuliano V, Schweitzer ME, O’Hara BJ (1997) Rheumatoid Nodules: MR/Pathological Correlation. J Comput Assist Tomogr 21(5): 796-799.

10. Mavrogenis D, Mavrogenis D, Psychikon N (2008) Skeletal Osteochondromas Revisited. Orthopedics 31(10): 1018-1029.

\section{Your next submission with Juniper Publishers will reach you the below assets}

- Quality Editorial service

- Swift Peer Review

- Reprints availability

- E-prints Service

- Manuscript Podcast for convenient understanding

- Global attainment for your research

- Manuscript accessibility in different formats ( Pdf, E-pub, Full Text, Audio)

- Unceasing customer service

Track the below URL for one-step submission https://juniperpublishers.com/online-submission.php 